Sādhanā Vol. 37, Part 5, October 2012, pp. 579-586. (C) Indian Academy of Sciences

\title{
Microstructure and microhardness of AA1050/TiC surface composite fabricated using friction stir processing
}

\author{
A THANGARASU ${ }^{1}, \mathrm{~N} \mathrm{MURUGAN}^{2}$, I DINAHARAN $^{3, *}$ and \\ S J VIJAY ${ }^{3}$ \\ ${ }^{1}$ Department of Mechanical Engineering, Sri Ramakrishna Institute of Technology, \\ Coimbatore 641010, India \\ ${ }^{2}$ Department of Mechanical Engineering, Coimbatore Institute of Technology, \\ Coimbatore 641014, India \\ ${ }^{3}$ School of Mechanical Sciences, Karunya University, Coimbatore 641114, India \\ e-mail: dinaweld2009@gmail.com
}

MS received 7 March 2012; revised 17 July 2012; accepted 1 August 2012

\begin{abstract}
Friction stir processing (FSP) has been developed by several researchers to produce an upper surface modification of metallic materials. The fabrication of TiC particulate $(\sim 2 \mu \mathrm{m})$ reinforced aluminum matrix composite (AMC) using FSP is studied in this paper. The measured content of $\mathrm{TiC}$ powders were compacted into a groove of $0.5 \mathrm{~mm} \times 5.5 \mathrm{~mm}$. A single pass FSP was carried out using a tool rotational speed of $1600 \mathrm{rpm}$, processing speed of $60 \mathrm{~mm} / \mathrm{min}$ and axial force of $10 \mathrm{kN}$. A tool made of $\mathrm{HCHCr}$ steel, oil hardened to $62 \mathrm{HRC}$, having a cylindrical profile was used in this study. The microstructure and microhardness of the fabricated AMC were analysed. Scanning Electron Microscope (SEM) micrographs revealed a uniform distribution of $\mathrm{TiC}$ particles which were well-bonded to the matrix alloy. The hardness of the AMC increased by $45 \%$ higher than that of the matrix alloy.
\end{abstract}

Keywords. Surface composite; friction stir processing; TiC.

\section{Introduction}

Aluminum matrix composites (AMCs) reinforced with ceramic particles exhibit high strength, high elastic modulus, and improved resistance to wear, creep and fatigue compared to unreinforced metals which make them promising structural materials for aerospace and automobile industries. However, these composites suffer a great loss in ductility and toughness due to the incorporation of non-deformable ceramic reinforcements which limits their wide applications to a certain extent (Miracle 2005). The surface properties dictate the life span of components in several applications. A combination of high surface wear resistance and high toughness of the

*For correspondence 
interior bulk material is required to prolong the life span. This balance of properties is not achievable in monolithic or homogeneous materials. Therefore, it is desirable to reinforce the surface layer of components with ceramic particles while the bulk material retains the original composition and structure with higher toughness. Such modified surface layer is known as surface metal matrix composites (SMMCs).

Several surface modification techniques such as high energy laser beam, plasma spraying, cast sinter and electron beam irradiation have been developed over the last two decades to fabricate SMMCs (Verezub et al 2011; Laha et al 2004; Wang et al 2000; Yun et al 2005). Those techniques are based on liquid phase processing at high temperature. It is hard to avoid the excessive interfacial reactions of reinforcement with metal matrix and resulting in the formation of some detrimental phases. A critical control of processing parameters is necessary to obtain ideal solidified microstructure in the surface layer. Those limitations can be overcome if processing of surface composite is carried out in the solid state.

Friction stir processing (FSP) is an emerging novel processing technique to fabricate surface composites which is based on the basic principles of friction stir welding (FSW). The distinct advantages of the FSP are microstructural refinement, densification, homogeneity, accurate control and variable depth of the processed zone. FSP is a green and energy efficient technique without deleterious gas and does not change the shape and size of the processed components (Ma 2008; Mishra \& Ma 2005).

Mishra et al (2003) first demonstrated the application of FSP technology to fabricate AA5083/SiC SMMC. The incorporation of SiC particles on the surface was successful and bonded well with the matrix. Subsequently, FSP evolved as a promising candidate to fabricate SMMC.

Some investigators reported the fabrication of SMMCs by FSP. Mahmoud et al (2008) fabricated AA1050/SiC SMMC and analysed the effect of tool rotational speed, processing speed and number of passes. The distribution of $\mathrm{SiC}$ particles became more homogeneous with increasing number of passes. Certain combinations of tool rotational speed and processing speed resulted in the formation of defects such as voids and tunnels in the FSP zone. Mahmoud et al (2009) fabricated AA1050/SiC SMMC and assessed the effect of tool pin size and profile. A square profile pin yielded finer distribution of $\mathrm{SiC}$ particles. The wear rates of flat surface tools were higher than that of the round shaped tools. Wang et al (2009) produced Al/1.5 vol.\% SiC SMMC and the distribution of $\mathrm{SiC}$ particles were observed $1.5 \mathrm{~mm}$ beyond the tool pin diameter. Yang et al (2010) developed $\mathrm{AA} 6061 / \mathrm{Al}_{2} \mathrm{O}_{3}$ nano SMMC and studied the effect of axial force and number of passes. The FSP zone became larger when axial force and the number of passes were increased. Zahmatkesh and Enayati (2010) produced $\mathrm{Al} / 10$ vol.\% $\mathrm{Al}_{2} \mathrm{O}_{3}$ nano SMMC and the nano $\mathrm{Al}_{2} \mathrm{O}_{3}$ particles were homogeneously distributed and remarkably improved the wear resistance of the alloy. Yadav \& Bauri (2011) developed AA1050/Ni SMMC and observed grain refinement of the matrix alloy. The composite exhibited a three-fold increase in $0.2 \%$ proof stress while an appreciable amount of ductility was retained.

In the present work, an attempt is made to fabricate AA1050/10wt. \% TiC surface composite to a depth of $5.8 \mathrm{~mm}$ on a $10 \mathrm{~mm}$ thick AA1050 plate and study the microstructure and hardness distribution of the same.

\section{Experimental procedure}

Commercially pure (98.2\%) 1050 aluminum which had iron, silicon, manganese and copper as major impurities was chosen as matrix material in the form of $10 \mathrm{~mm}$ thick plate. The nominal 
Table 1. Chemical composition of AA1050.

\begin{tabular}{lcccccccr}
\hline Element & $\mathrm{Mg}$ & $\mathrm{Si}$ & $\mathrm{Fe}$ & $\mathrm{Mn}$ & $\mathrm{Cu}$ & $\mathrm{Zn}$ & $\mathrm{Ti}$ & Aluminum \\
\hline wt.\% & 0.05 & 0.25 & 0.40 & 0.13 & 0.05 & 0.05 & 0.03 & Balance \\
\hline
\end{tabular}

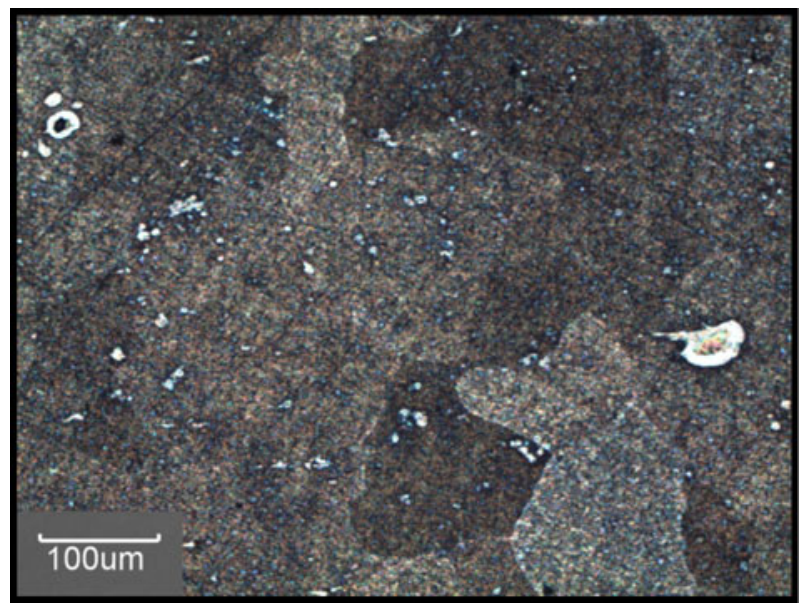

Figure 1. Optical photomicrograph of AA1050.

composition of AA1050 is given in table 1. Figure 1 shows the microstructure of AA1050. A groove of $0.5 \mathrm{~mm}$ in width, $5.8 \mathrm{~mm}$ in depth and $100 \mathrm{~mm}$ in length was made on the plate and filled with TiC powder $(\sim 2 \mu \mathrm{m})$. Figure 2 shows the SEM photomicrograph of as received TiC powder. A tool made of $\mathrm{HCHCr}$ steel; oil hardened to $62 \mathrm{HRC}$, having a cylindrical profile was used. The tool had a shoulder diameter of $18 \mathrm{~mm}$, pin diameter of $6 \mathrm{~mm}$ and pin length

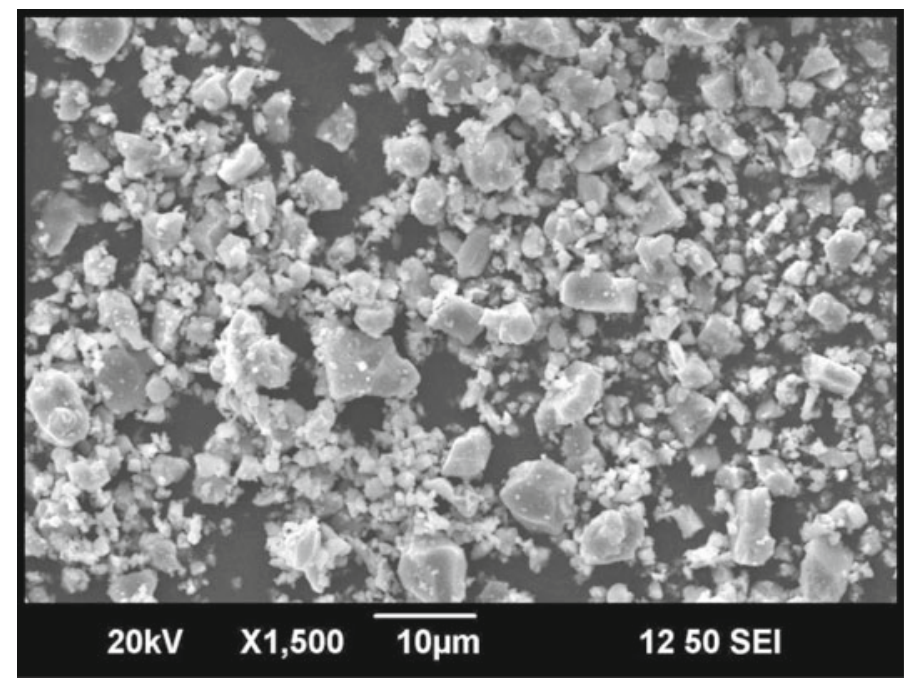

Figure 2. SEM photomicrograph of TiC powder. 


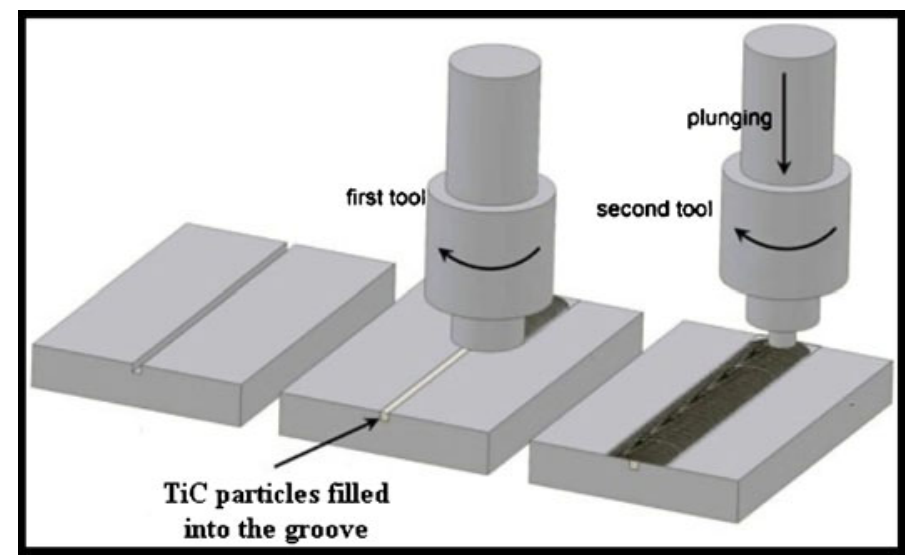

Figure 3. Schematic illustration of FSP steps.

of $5.8 \mathrm{~mm}$. The FSP was carried out at a rotational speed of $1600 \mathrm{rpm}$ and a traverse speed of $60 \mathrm{~mm} / \mathrm{min}$. A downward force of $10 \mathrm{kN}$ was applied on the tool. The FSP was carried out on an indigenously built FSW machine (M/s RV Machine Tools, Coimbatore, India). FSP procedure is schematically shown in figure 3. A pinless tool was initially employed to cover the top of the grooves after filling with TiC particles to prevent the particles from scattering during FSP.

A specimen was prepared perpendicular to the FSP direction to carry out microstructural and mechanical characterization. The specimen was polished as per standard metallographic procedure and etched with Keller's reagent. The microstructure was observed using scanning electron microscope (JEOL-JSM-6390). The microhardness was measured using a microhardness tester (MITUTOYO-MVK-H1) at $500 \mathrm{~g}$ load applied for $15 \mathrm{~s}$ along the cross section of the specimen.

\section{Results and discussions}

Figure 4 shows the upper surface appearance of the fabricated SMMC. The groove is effectively closed subsequent to FSP. Defects such as voids and cracks are not observed on the surface. The

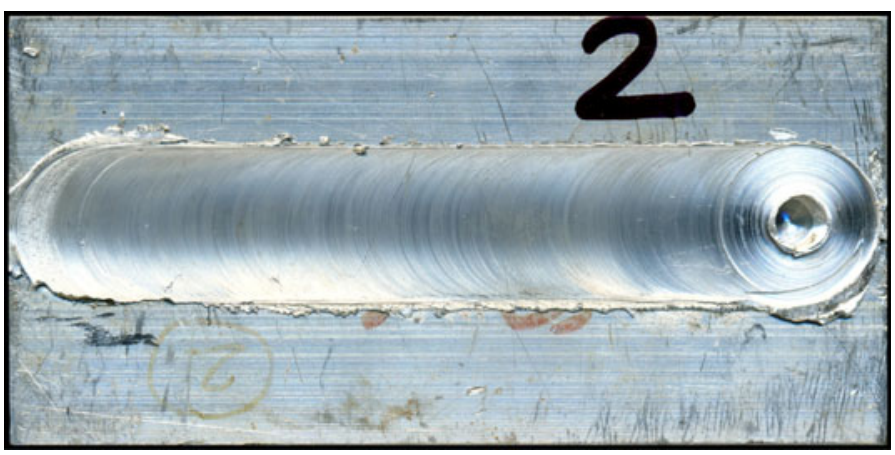

Figure 4. Crown appearance of FSP zone of AA1050/TiC SMMC. 
top surface shows very smooth quality and there is almost no prominences or depressions inspite of tool's stirring. The groove size is sufficient to produce sound SMMC.

\subsection{Microstructures}

Figure 5 shows the macrograph of the FSP zone. A defect-free FSP zone is observed. Typical FSW defects (tunnel, pin hole, piping and worm hole) are absent. It is evident from the macrograph that the groove is completely bonded on all sides. The pin length is $0.3 \mathrm{~mm}$ higher than that of the groove depth which proves to be adequate to produce full penetration. Hence defects do not arise at the bottom side of the groove. The rubbing of the tool on the substrate generates frictional heat which plasticizes the alloy which reaches semi solid state (Mishra \& Ma 2005). The vigorous stirring action of the tool distributes the packed TiC particles into the plasticized alloy. The translation of the tool moves the plasticized composite from advancing side to retreading side and forges at the back of the tool. Thus, SMMC is produced by FSP. The FSP zone is typically about the size of the rotating pin, namely width and depth of $6 \mathrm{~mm}$ and $5.8 \mathrm{~mm}$, respectively.

Figure 6 shows the SEM micrographs of the interface zone at the retreading side between surface composite and aluminum alloy substrate. The surface composite layer appears to be well-bonded to the aluminum alloy substrate and no defects are visible at the interface. A narrow thermomechanically affected zone (TMAZ) is observed. TMAZ exhibits the distribution of $\mathrm{TiC}$ particles along parallel bands in the aluminum matrix. The frictional heat generated by the rotating tool and application of high stresses during the FSP lead to stretching of TiC particles along the shear stress directions.

Figure 7 shows the SEM micrographs of FSP zone. TiC particles are homogenously distributed in the FSP zone. The grain size of the aluminum alloy has obviously been refined by FSP. A homogenous distribution of ceramic particles is essential to attain higher mechanical properties in SMMC. Stirring causes higher plastic strain which results in rearrangement of TiC particles. FSW can be considered as a hot-working process in which severe plastic deformation is imported to the work piece through the rotating pin and shoulder. The size of TiC particles is not uniform throughout the FSP zone. Comminution of ceramic particles was widely acknowledged in FSW of aluminum matrix composites (Marzoli et al 2006; Ceschini et al 2007; Nami et al 2010). Those investigators reported the blunting of sharp edges of $\mathrm{Al}_{2} \mathrm{O}_{3}$ or $\mathrm{SiC}$ particles $(>20 \mu \mathrm{m})$ which resulted in the formation of fine debris in the weld zone. The difference in size of particles in the SMMC as seen in figure 7 is least which indicates little or no comminution during FSP.

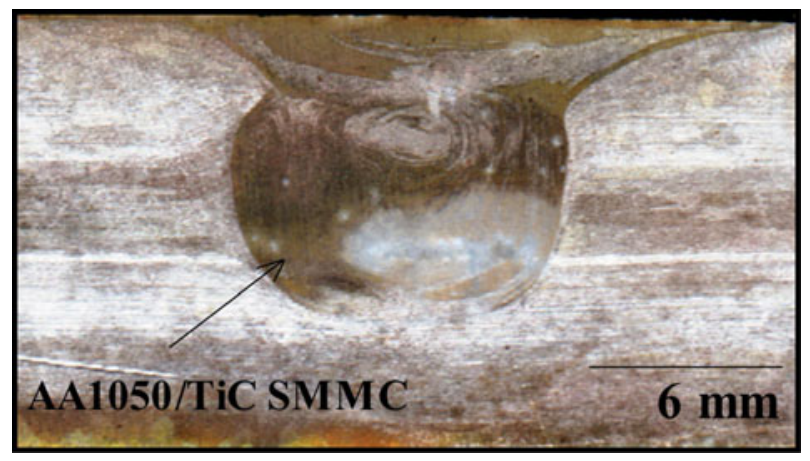

Figure 5. Macrograph of FSP zone. 


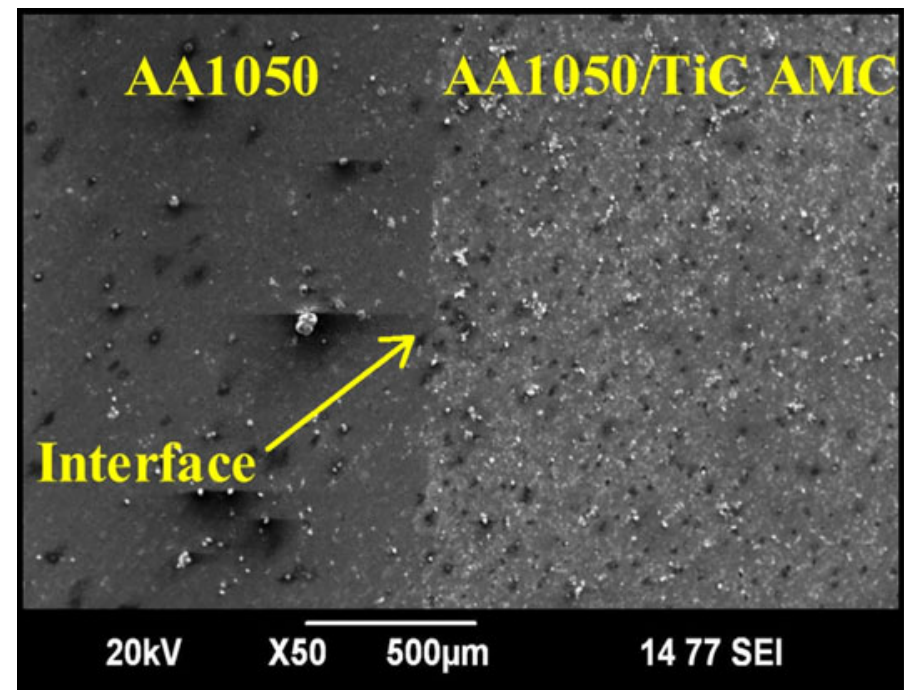

Figure 6. SEM photomicrograph of interface zone.

This can be attributed to the initial morphology and size (figure 2) of TiC particles. TiC particles had a minimum number of sharp edges and less than $5 \mu \mathrm{m}$ in size which resulted in little or no comminution. The nucleation sites are increased with the presence of the reinforcement particles which lead to the reduction of aluminum matrix grain size.

\subsection{Microhardness}

Figure 8 shows the microhardness distribution in the base alloy and composite. TiC particles enhanced the hardness of aluminum alloy. The average hardness of FSP zone is $45 \%$ higher than that of the aluminum alloy. The possible strengthening mechanisms which may operate in SMMC are as follows (Zarghani et al 2009).

(i) Orowan strengthening.

(ii) Grain and substructure strengthening.

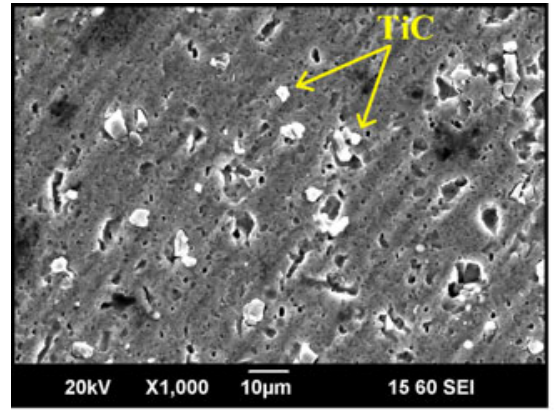

(a)

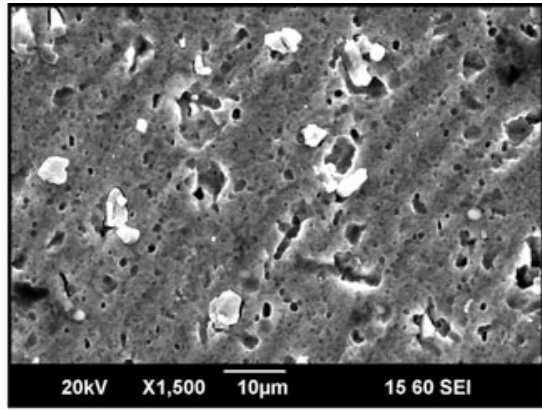

(b)

Figure 7. (a) and (b) SEM photomicrograph of AA1050/TiC SMMC. 


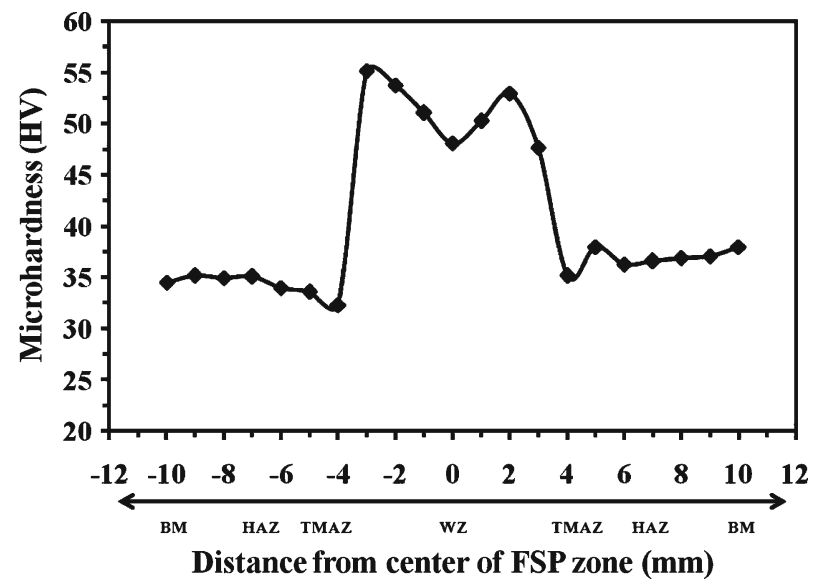

Figure 8. Microhardness distribution in the base metal and composite.

(iii) Quench hardening resulting from the dislocations generated to accommodate the differential thermal contraction between the reinforcing particles and the matrix.

(iv) Work hardening due to the strain misfit between the elastic reinforcing particles and the plastic matrix.

According to the characteristics of the microstructure, the major contributions to the hardness of the surface composite layer fabricated by FSP are is Orowan strengthening due to the fine dispersion of TiC particles and good bonding to matrix alloy.

The peak hardness is observed away from the center at the advancing and retreating sides. A similar kind of hardness profile showing peak hardness away from the center of the stir zone was reported earlier by Yadav \& Bauri (2011). The material flows in a complex fashion from the retreating to the advancing side during FSP giving rise to gradients in temperature, strain and strain rate across the stir zone. This in turn gives rise to different microstructural features at different locations in the stir zone. Moreover, since a groove was made at the center of the aluminum plate to incorporate the $\mathrm{TiC}$ particles, the material has to flow into the groove to fill it to give a defect-free continuous stir zone. Hence, friction stir welding and processing both take place at the center while only friction stir processing takes place away from the center. Therefore, the center may experience less deformation compared to the sides. This may also be responsible for the hardness drop at the center.

\section{Conclusion}

AA1050/TiC SMMC was fabricated using FSP. The fabricated AA1050/TiC composite layer was well-bonded to the aluminum substrate. TiC particles were distributed homogeneously in the FSP zone. The hardness of the FSW zone increased by $45 \%$ higher than that of the matrix alloy.

\section{Acknowledgements}

The authors are thankful to the Management, Coimbatore Institute of Technology (CIT), Coimbatore, India. The authors also thank the Naval Research Board, Govt. of India for financial 
support. One of the authors, Mr. I. Dinaharan thanks the Department of Science and Technology (DST), Govt. of India for providing INSPIRE fellowship.

\section{References}

Ceschini L, Boromei I, Minak G, Morri A and Tarterini F 2007 Effect of friction stir welding on microstructure, tensile and fatigue properties of the AA7005/10 vol. $\% \mathrm{Al}_{2} \mathrm{O}_{3}$ p composite. Compos. Sci. Technol. 67: 605-615

Laha T, Agarwal A, McKechnie T and Seal S 2004 Synthesis and characterization of plasma spray formed carbon nanotube reinforced aluminum composite. Mater. Sci. Eng. A 381: 249-25

Ma Z Y (2008) Friction stir processing technology: a review. Met. Mater. Trans. A 69: 642-658

Mahmoud E R I, Ikeuchi K and Takahashi M 2008 Fabrication of SiC particle reinforced composite on aluminium surface by friction stir processing. Sci. Technol. Weld Joining 13: 607-618

Mahmoud E R I, Takahashi M, Shibayanagi T and Ikeuchi K 2009 Effect of friction stir processing tool probe on fabrication of SiC particle reinforced composite on aluminium surface. Sci. Technol. Weld Joining 14: 413-425

Marzoli L M, Strombeck A V, Santos J F D, Gambaro C and Volpone L M 2006 Friction stir welding of an AA6061/Al2O3/20p reinforced alloy. Compos. Sci. Technol. 66: 363-371

Miracle D B 2005 Metal matrix composites - From science to technological significance. Compos. Sci. Technol. 65: 2526-2540

Mishra R S and Ma Z Y 2005 Friction stir welding and processing. Mater. Sci. Eng. R 50: 1-78

Mishra R S, Ma Z Y and Charit I 2003 Friction stir processing: a novel technique for fabrication of surface composite. Mater. Sci. Eng. A 341: 307-310

Nami H, Adgi H, Sharifitabar M and Shamabadi H 2010 Microstructure and mechanical properties of friction stir welded Al/ $\mathrm{Mg}_{2} \mathrm{Si}$ metal matrix cast composite. Mater. Des. 32: 976-983

Verezub O, Kálazi Z, Sytcheva A, Kuzsella L, Buza G, Verezub NV, Fedorov A and Kaptay G 2011 Performance of a cutting tool made of steel matrix surface nano-composite produced by in situ laser melt injection technology. J. Mater. Process Technol. 211: 750-758

Wang Y, Zhang X, Zeng G and Li F 2000 Cast sinter technique for producing iron base surface composites. Mater. Des. 21: 447-452

Wang W, Shi Q, Liu P, Li H and Li T 2009 A novel way to produce bulk SiCp reinforced aluminum metal matrix composites by friction stir processing. J. Mater. Process Technol. 209: 2099-2103

Yadav D and Bauri R 2011 Processing, microstructure and mechanical properties of nickel particles embedded aluminium matrix composite. Mater. Sci. Eng. A 528: 1326-1333

Yang M, Xu C, Wu C, Lin K, Chao Y J and An L 2010 Fabrication of AA6061/ $\mathrm{Al}_{2} \mathrm{O}_{3}$ nano ceramic particle reinforced composite coating by using friction stir processing. J. Mater. Sci. 45: 4431-4438

Yun E, Lee K and Lee S 2005 Correlation of microstructure with high-temperature hardness of (TiC,TiN)/Ti-6Al-4V surface composites fabricated by high-energy electron-beam irradiation. Surf. Coat Technol. 191: 83-89

Zahmatkesh B and Enayati M H 2010 A novel approach for development of surface nanocomposite by friction stir processing. Mater. Sci. Eng. A 527: 6734-6740

Zarghani A S, Bozorg S F K and Hanzaki A Z 2009 Microstructures and mechanical properties of $\mathrm{Al} / \mathrm{Al}_{2} \mathrm{O}_{3}$ surface nano-composite layer produced by friction stir processing. Mater. Sci. Eng. A 500: 84-91 